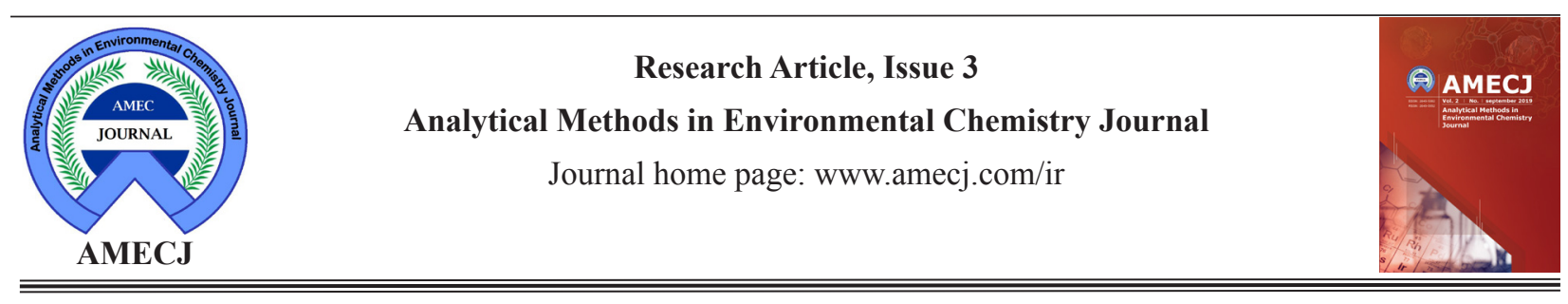

\title{
Air pollution Analysis: Nickel paste on Multi-walled carbon nanotubes as novel adsorbent for the mercury removal from air
}

\author{
Ali Ebrahimia,"* and Ahmad Salarifar ${ }^{\mathrm{b}}$ \\ a, ${ }^{*}$ Occupational Health Engineering Department, School of Public Health, Qom University of Medical Sciences, Qom, Iran. \\ ${ }^{\mathrm{b}}$ Environmental Engineering, Faculty of Natural Resources, Islamic Azad University, Bandar Abbas Branch, Bandar Abbas, Iran
}

A R T I C LE IN F O:

Received 13 Jul 2019

Revised from 17 Aug 2019

Accepted 2 Sep 2019

Available online 28 Sep 2019

Keywords:

Mercury,

Removal from air,

Nickel coated on multi-walled

carbon nanotubes,

Adsorption,

Solid-gas phase removal

\begin{abstract}
A B S T RAC T
Mercury as a hazardous material can be released in air and caused renal failure and CNS problem in humans. In this study, mercury vapor removed from air based on nickel-coated on multi-walled carbon nanotubes (Ni-MWCNTs) as a novel sorbent at room temperature. By procedure, amalgamation of mercury with Ni-MWCNTs was achieved by solid-gas phase removal method (SGPR). In bench scale set up, the mercury vapor generated and mixed with purified air with electro air cleaner and moved to sorbent at optimized flow rate. After thermal desorption of Ni-MWCNTs at $200{ }^{\circ} \mathrm{C}$, the mercury vapor flowed to quartz glass cell with argon gas and determined by cold vapor atomic absorption spectrometer technique (CV-AAS). In optimized conditions, $25 \mathrm{mg}$ of Ni-MWCNTs and MWCNTs with different size from 30-100 nm was used and the adsorption capacity of sorbents was obtained $194 \mathrm{mg} \mathrm{g}^{-1}$ and $64 \mathrm{mg} \mathrm{g}^{-1}$, respectively. The efficient recovery was obtained at optimized conditions such as, temperature of $25-40$ and flow rate of $200 \mathrm{~mL} \mathrm{~min}{ }^{-1}$. Due to results, the surface of Ni-MWCNTs had good potential for removal of mercury vapor from the air and can be used as a low cost and efficient sorbent in industrial workplace.
\end{abstract}

\section{Introduction}

Mercury was ranked as a hazardous material for human health and animals such black fish and extra concentration cause dangers disease in human body [1,2]. Mercury is a toxic element and has no essential biological function in human body and normal range was reported less than $20 \mu \mathrm{g} \mathrm{L}^{-1}$ and $2 \mu \mathrm{g} \mathrm{L}^{-1}$ in urine and blood serum, respectively by ACGIH. Organic and inorganic mercury occurs in fishes, foods, vegetables, waters and air [3].

Corresponding Author: Ali Ebrahimi *

E-mail: a_ebrahimi2010@yahoo.com

Ali.Ebrahimi.ohe@gmail.com

https://doi.org/10.24200/amecj.v2.i03.70
It is emitted to the atmosphere from chlor-alkali factory, sea, chemical process, coal, oil combustion for energy generation, and metal mining, The contribution of industrial sources for mercury and other heavy metals emissions to the atmosphere, rivers and fish and humans [4]. Human exposure to mercury evaluated and studied in occupational and environmental health [5]. Mercury generated from chemicals, petrochemical and electrical industries [6]. The mercury exposure caused many health problems in human body such as, central nervous system defects, erythrism, arrhythmias, cardiomyopathies, and kidney damage. Necrotizing 
bronchitis and pneumonitis arising from inhalation of mercury vapor can result in respiratory failure $[5,6]$. Mercury is listed and suggested as one of the hazardous air pollutants in the 1990 and recently many methods was used for mercury removal from air [7]. The air sampling and analysis methods was used for mercury determination by the national institute for occupational safety and health (NIOSH) and the occupational safety and health administration (OSHA), respectively(NIOSH 6009). The main disadvantages of these methods related to interference by other metal compounds and organic mercury in air. the sample tube be The fragile of sample tube, low adsorption capacity, impurities and contamination of reagents used for sample preparation, the use of nitric acid and hydrochloric acid, as well as being time consuming, the mercury loss during sample preparation, operator skills and the costs of solid sorbent tubes caused to consider as a weak procedure $[8,9]$. Many Nano carbon compound such as carbon nanotubes (MWCNTs, SWCNTs), graphene and mesoporous silica nanoparticles (MSN) was syntheses and used as a sorbent for removal of mercury from air. Carbon nanotubes are unique wall porous structures with nanometer diameter and can be simply removed mercury from air with two type's single walled carbon nanotubes (SWNTs) and multiple walled carbon nanotubes (MWNTs) [16]. MWCNT and SWCNT were used in many published papers for mercury removal from air/gas. Adsorption of mercury was achieved by montmorillonite powder modified with Copper Compounds or amorphous of $\mathrm{MoS}_{3}$ pasted on $\mathrm{TiO}_{2}$ was used for removal metals from gas/air. Also, the bimetallic sorbents such as $\mathrm{Pd}-\mathrm{Fe}$ and catalytic compounds such as $\mathrm{Ce}-\mathrm{Mn} / \mathrm{TiO}_{2}$ applied for $\mathrm{Hg}^{0}$ removal in air [10-15]. In fact, CNTs with chemical and physical properties have good potentially in many applications such as, nanotechnology, electronics, optics, water, chemistry, environment and other fields of materials science [16-20]. Low diameter (nm), low weight, thermal conductivity and high surface area, thermal resistance, high tensile strength and a very high Young modulus caused to introduce as novel adsorbent in many science [21-22]. Also, these compounds also have been used for absorb the gases and metal cations and volatile organic compounds [23-27]. The carbon nanotubes have a good repeatability in high temperature, So, CNTs introduce a favorite sorbent for mercury removal from air by thermal desorption method [28, 29], Also, the health effect of exposure to solvents, acids and other chemical methods were reduced by proposed method. Recently, different instruments coupled with techniques was reported for mercury analysis by researchers, activated carbon from mixed recyclable waste modified by phosphonium-based ionic liquid (IL-ACMRW) based on Inductively Coupled Plasma- mass spectroscopy (ICP-Ms) was used for mercury removal from wastewater. Inductively coupled plasma atomic emission spectroscopy (ICP OES), high-performance liquid chromatography coupled hydride generation atomic absorption spectrometry (HPLC-HG-AAS), hydride generation atomic absorption spectrometry ( $H G$-AAS), hydride generation atomic absorption spectrometry coupled mercury concentration (HG-AAS-MC3000). In this work, Ni-MWCNTs and MWCNTs was removed the mercury vapor from air due to their unique physicochemical properties. Strong chemical interactions between $\mathrm{Ni}$ and $\mathrm{Hg}^{\circ} \quad(\mathrm{Hg} \rightarrow \mathrm{Ni}-$ MWCNTs) caused to increase removal efficiency of sorbent by SGPR. The reusable of Ni-MWCNTs can be considered as a cost effective sorbent.

\section{Experimental}

\subsection{Material and Methods}

All reagents such as, Sodium borohydride, nitric acid, sodium hydroxide and hydrochloric acid were prepared from Sigma Aldrich. Mercury standard solutions were prepared from a stock solution of $1000 \mathrm{mg} \mathrm{L}^{-1}$ in $1 \%$ ultra-pure nitric acid. Working standard solutions were freshly prepared by dilution of stock and intermediate standards. Sodium borohydride $\left(\mathrm{NaBH}_{4}\right)$ prepared fresh daily. $3.0 \mathrm{~g}$ of $\mathrm{NaBH} 4$ and $3.0 \mathrm{~g}$ of sodium hydroxide $(\mathrm{NaOH})$ were mixed and diluted by deionized water (DW) up to $500 \mathrm{~mL}$. Deionized water obtained from a 
water purification system (Millipore, Bedford, MA, USA) was used for preparing all solutions. All containers (quartz crucibles, plastic tubes) were cleaned with detergent and treated successively by the hydrochloric acid and rinsed with deionized water. Argon was used as the pure gas (99.99\%). The present research is an experimental study and it includes stages such as preparation of the various concentrations of mercury vapor, adsorption of mercury vapor in various concentration, time, temperature optimized as well as retention time of adsorbed mercury by multi-walled carbon nanotubes. The atomic absorption spectrometer (GBC) Model (AAS-932 Puls) with cold vapor technique (CV-AAS/HG3000) has been used for the analysis of samples. Instrumental parameters for cold vapor atomic absorption spectrometry are shown in Table 1. The mercury concentrations were prepared from $1 \mu \mathrm{gL}^{-1}$ to $50 \mu \mathrm{gL}^{-1}$. The NiMWCNTs $(25 \mathrm{mg})$ as solid phase was used and placed in a glass tube with length of $5 \mathrm{~cm}$ and the internal and external diameters of 5 and $8 \mathrm{~mm}$ respectively. Then, end-capping with some silica /cotton was performed to prevention of humidity. MWCNTs were provided by Nano department of RIPI, Tehran. Also, all solutions and materials were purchased from Merck, Germany.

\subsection{Synthesis of nickel coated on MWCNTs}

The Ni-MWCNTs has prepared as follows, 2.0 $\mathrm{g}$ of the pure MWCNTs was added to $50 \mathrm{~mL}$ of DW with $0.25 \mathrm{~g}$ of Sodium sulfosuccinate esters ( $\mathrm{NaO}_{3} \mathrm{SCH}\left(\mathrm{CO}_{2} \mathrm{R}^{\prime}\right) \mathrm{CH}_{2} \mathrm{CO}_{2} \mathrm{R}$ )as a surfactant by low heating at $300 \mathrm{rpm}$ stirring speed. The nickel nitrate $(0.5 \mathrm{~g})$ was added to the Final solution without heat in $200 \mathrm{rpm}$ stirring speed. Then, ammonia solution $(2 \mathrm{~mL})$ was added to solution and diluted with DW up to $200 \mathrm{~mL}$ with stirring in $20 \mathrm{~min}$ at $300 \mathrm{rpm}$ speed. Then finally, $10 \mathrm{~mL}$ of formalin slowly was added for five minutes as a reducing agent. The synthesis of Ni-MWCNTs nanoparticles was obtained by increasing the speed of Stirring after addition formalin for $10 \mathrm{~min}(800$ rpm). The extra formalin and ammonia on NiMWCNTs cleaned by DW washing after filtration
Table 1. Conditions of cold vapor atomic absorption spectrometry (CV-AAS) for mercury

\begin{tabular}{ll}
\hline Parameters & Value \\
\hline $5 \mathrm{~mA}$ & Lamp Current \\
$253.7 \mathrm{~nm}$ & Wavelength \\
$0.5 \mathrm{~nm}$ & Band pass \\
Cold vapor & Flame Conditions \\
$\mathrm{HCL}$ & Lamp \\
$400 \mathrm{k} \mathrm{Pa}$ & Argon gas pressure \\
$100 \mathrm{~mL} / \mathrm{min}$ & Gas flow to the mixer block \\
$35 \mathrm{~mL} / \mathrm{min}$ & Gas flow to the separator \\
\hline
\end{tabular}

by Whatman filter. In addition, oxidation of the NiMWCNTs nanoparticles was prevented by washing with Ethanol.

\subsection{Experimental Procedure}

In bench scale set up, the air was purified with electro air cleaner (EAC, Canada, model EAHEPA600M-3) by HEPA. The HEPA act for efficient removing particles under $300 \mathrm{~nm}$ (99.97\%) from air. Then, the pure air of EAC passed through polyethylene tubes and entered to polyethylene bag (1 Li) by a SKC pump. All of the gas lines were PE tubes and those that enter to PE bag were covered with heating jackets capable of controlling the temperature at $50{ }^{\circ} \mathrm{C}$ to prevent water vapor and mercury vapor from condensing. In SGPR, trace of elemental mercury vapor in air was prepared by aqueous standard solution of mercury $\left(1-50 \mu \mathrm{gL}^{-1}\right)$. The aqueous standard solutions entered to hydride generator system and mercury vapor generated in a continuous flow rate. The system was designed by a peristaltic pump that can be pumped standard solutions of mercury, tin chloride as reducing agent and ionized water into a mixer continuously. Peristaltic pump rotation rate was 1.5 rounds per second or $90 \mathrm{rpm}$. The solution mixed thoroughly in reaction tube and then pushed into a liquid-gas separator where the mercury vapor is separated from the liquid using an inert carrier gas. The mercury vapor mixed with pure air and flowed to Ni-MWCNT by flow rate 100-300 $\mathrm{ml} \mathrm{min}^{-1}$. After adsorption mercury by Ni-MWCNTs, the remained air stored in polyethylene bag $1(1 \mathrm{~L})$. The air into air bag was determined by CV-AAS and MC3000 


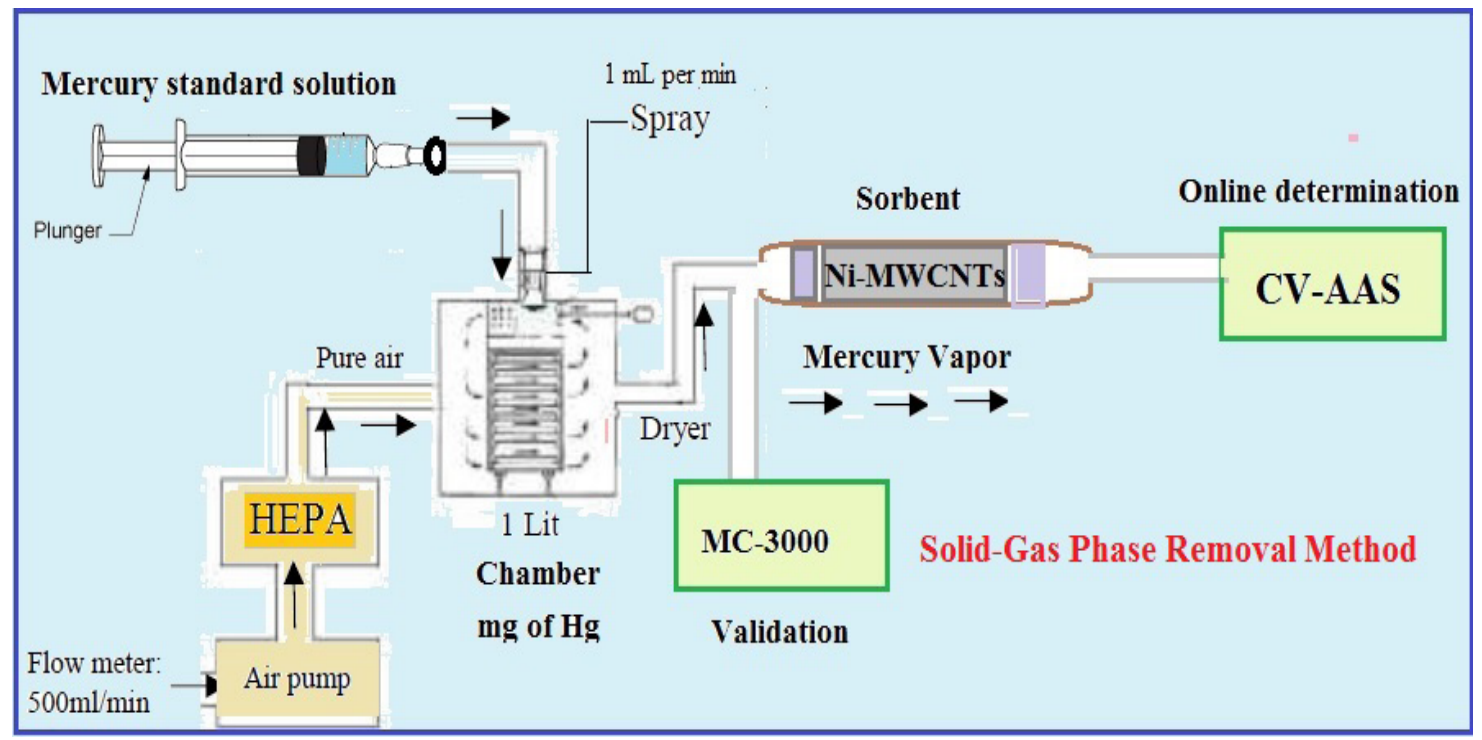

Fig. 1. Scheme of pilot plan for mercury removal from air

(gold trap). After thermal desorption of MWCNT, the mercury vapor flowed with Ar gas and stored in another bag (bag 2,1L) and mercury determined by CV-AAS and MC 3000. The pilot plan for mercury removal from air was shown in Figure 1.

\section{Results and Discussion}

\subsection{Scanning electron microscopy images from carbon nanotubes}

The scanning electron microscopy (SEM) and Transmission electron microscopy (TEM) images of MWCNT and Ni-MWCNTs was shown in
Figures 2 and 3, respectively. Elemental analysis conditions showed that Ni-MWCNTs included 8\% nickel and $90 \%$ carbon. Mercury was removed by sorbent $0.55 \%$ by Ni-MWCNTs (Table 2 ).

\subsection{Adsorption efficiency for different amounts of MWCNTs}

The adsorption efficiency with $25 \mathrm{mg}$ of $\mathrm{Ni}$ MWCNTs and MWCNTs was examined for 0.01-0.1 $\mu \mathrm{g}$ of mercury concentration by SGPR. According to the results, the adsorption efficiency for Ni-MWCNTs was more than $95 \%$ as compared
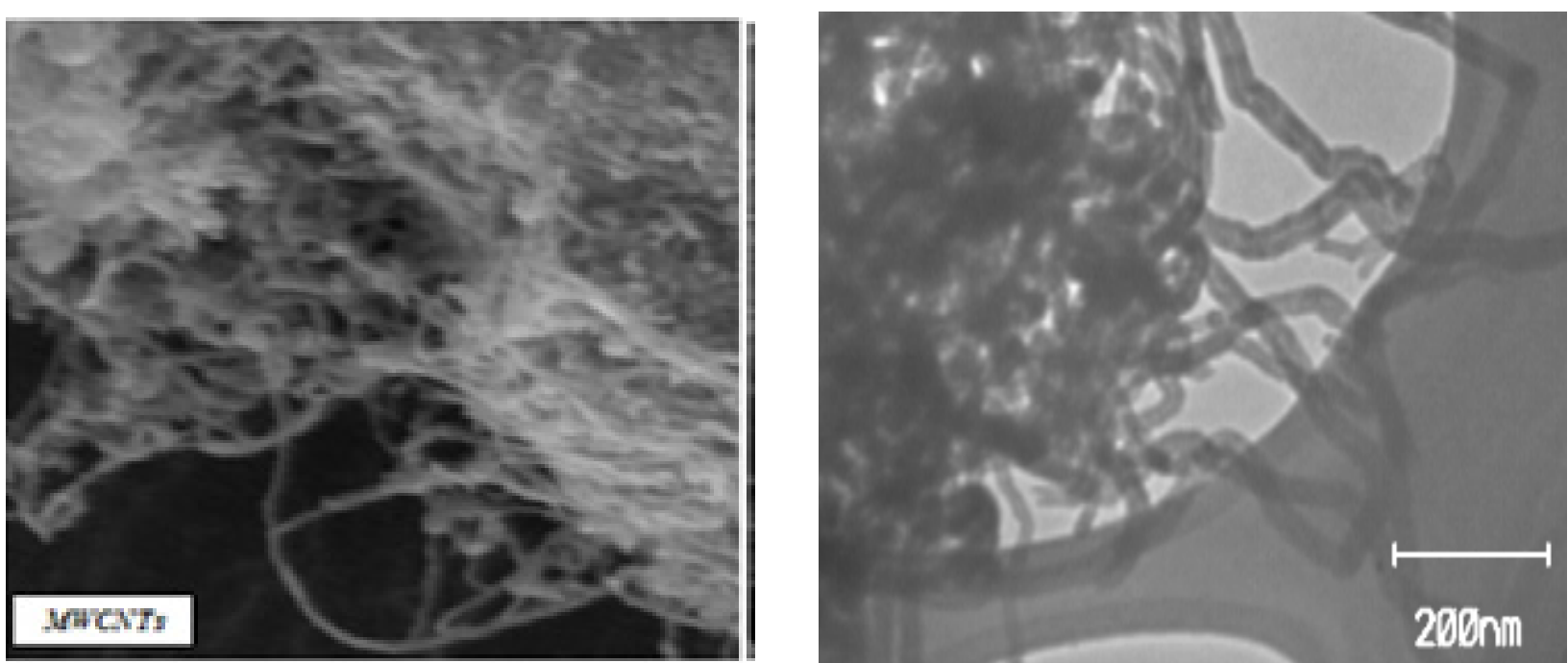

Fig. 2. SEM (L) and TEM (R) images of multi-walled carbon nanotubes 

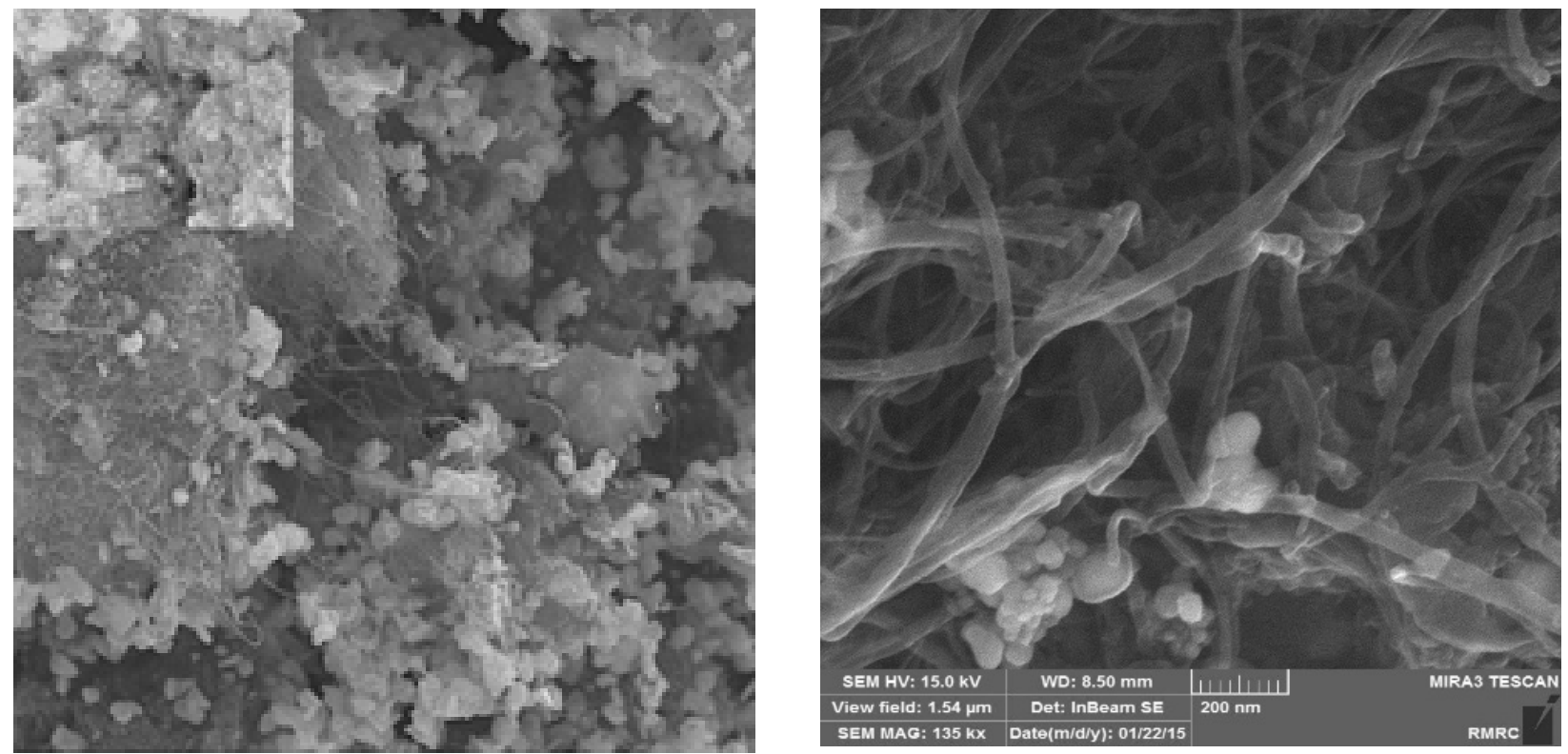

Fig. 3. SEM (L) and TEM (R) images of Nickel coated on multi-walled carbon nanotubes

Table 2. Energy Dispersive X-Ray Analysis of Ni-MWCNTs (EDX) for mercury removal

\begin{tabular}{|c|c|c|c|c|c|c|c|c|c|c|c|c|c|c|}
\hline EIt & Line & Int & Error & $\mathbf{K}$ & $\mathbf{K r}$ & W\% & A\% & ZAF & Ox\% & $\mathrm{Pk} / \mathrm{Bg}$ & Class & LConf & HConf & Cat\# \\
\hline $\mathrm{C}$ & $\mathrm{Ka}$ & 676.1 & 80.3865 & 0.4213 & 0.2945 & 48.21 & 90.22 & 0.6107 & 0.00 & 37.86 & A & 47.66 & 48.76 & 0.00 \\
\hline $\mathrm{Ni}$ & $\mathrm{La}$ & 1269.7 & 6.5990 & 0.4792 & 0.3350 & 41.14 & 8.57 & 0.8142 & 0.00 & 26.05 & A & 40.79 & 41.48 & 0.00 \\
\hline $\mathrm{Au}$ & $\mathrm{La}$ & 7.0 & 0.5642 & 0.0839 & 0.0586 & 9.29 & 1.06 & 0.6307 & 0.00 & 2.41 & B & 8.25 & 10.34 & 0.00 \\
\hline $\mathrm{Hg}$ & $\mathrm{Ma}$ & 47.1 & 6.5990 & 0.0157 & 0.0110 & 1.36 & 0.55 & 0.8077 & 0.00 & 3.20 & B & 1.30 & 1.42 & 0.00 \\
\hline
\end{tabular}

to MWCNTs (less than 70\%). Also the RSD had different value from 5 to $8 \%$. The results showed that the good recoveries for mercury removal by two sorbents were achieved in low and high mercury concentration (Table 3).

\subsection{Adsorption capacity of Ni- MWCNTs and MWCNTs}

In batch system, $10 \mathrm{mg} \mathrm{\textrm {L } ^ { - 1 }}$ of mercury standard solution (Merck) selected and injected in closed special glass (CSG) after put into Ni- MWCNTs

Table 3. Recovery of adsorption for different concentration of mercury from low to high range ( $n=10$; Mean SD of results \pm 0.0032 )

\begin{tabular}{cccc}
\hline \multicolumn{4}{c}{$25 \mathrm{mg}$ of NI-MWCNTs } \\
\hline Pilot concentrations $(\mu \mathrm{g})$ & Found desorption & RSD $\%$ & Recovery $(\%)$ \\
\hline 0.01 & 0.00944 & 0.67 & 94.4 \\
0.02 & 0.0195 & 0.52 & 97.5 \\
0.03 & 0.0286 & 0.73 & 95.3 \\
0.05 & 0.0487 & 0.81 & 97.4 \\
0.1 & 0.0976 & 0.76 & 97.6 \\
\hline 0.01 & $25 \mathrm{mg}$ of MWCNTs & 65.4 \\
0.02 & 0.00654 & 0.74 & 74.0 \\
0.03 & 0.0148 & 0.63 & 68.6 \\
0.1 & 0.0206 & 0.73 & 77.6 \\
\hline
\end{tabular}




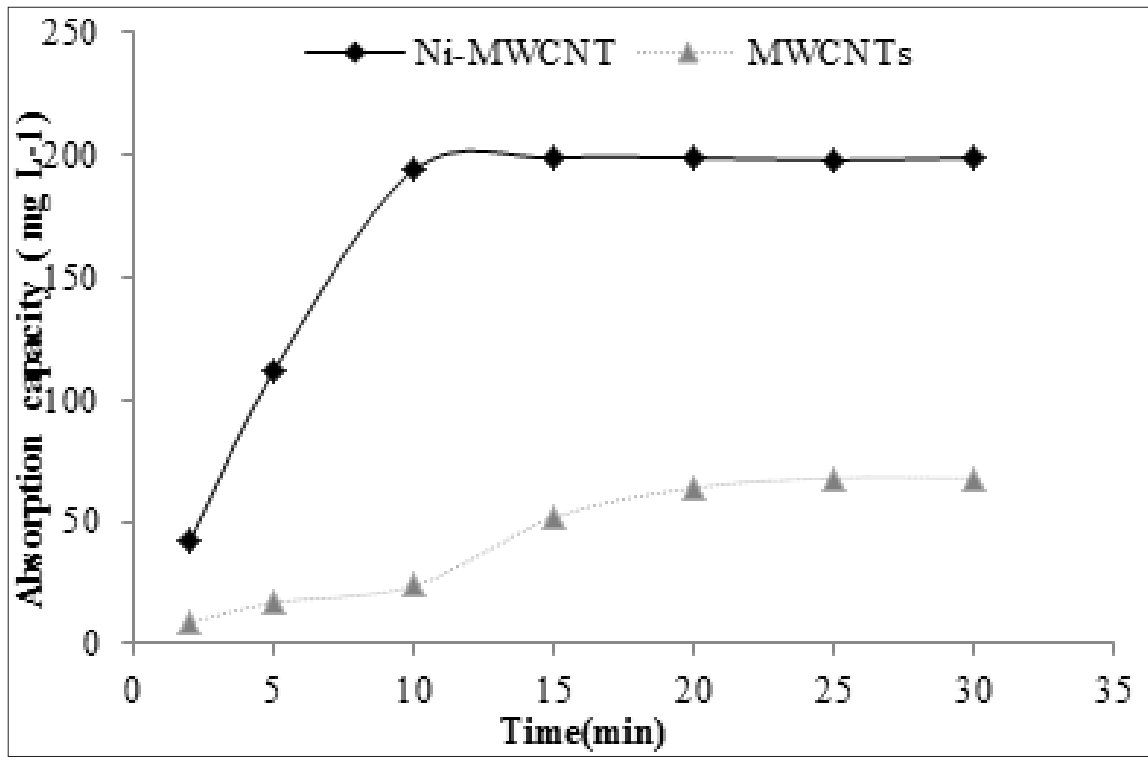

Fig. 4. The absorption capacity (AC) of mercury vapor in Ni- MWCNTs and MWCNTs (n=10).

and MWCNTs as sorbents in CSG. After heating, the temperature increased up to $80{ }^{\circ} \mathrm{C}$ for 10 min. The mercury was vapored and absorbed on sorbents. The results showed us, the absorption capacity (AC) of Ni- MWCNTs and MWCNTs for mercury removal was obtained $194.7 \mathrm{mg} \mathrm{g}^{-1}$ and $64.4 \mathrm{mg} \mathrm{g}^{-1}$, respectively (Fig. 4). In temperature of $50^{\circ} \mathrm{C}$ for $10 \mathrm{~min}, \mathrm{AC}$ was decreased about $8 \%$ but after 20 min AC was similar to proposed procedure.

\section{4: Determine the optimum time and temperature} for desorption

For optimization of temperature, the rate of desorption at different temperatures was studied by SGPR. The maximum of desorption rates on the Ni-MWCNTs was achieved in $160-250^{\circ} \mathrm{C}$. So, $200^{\circ} \mathrm{C}$ was selected as an optimum temperature for desorption point by Ni-MWCNT. Based on the optimum temperature and after several experiments, the results showed that the best time

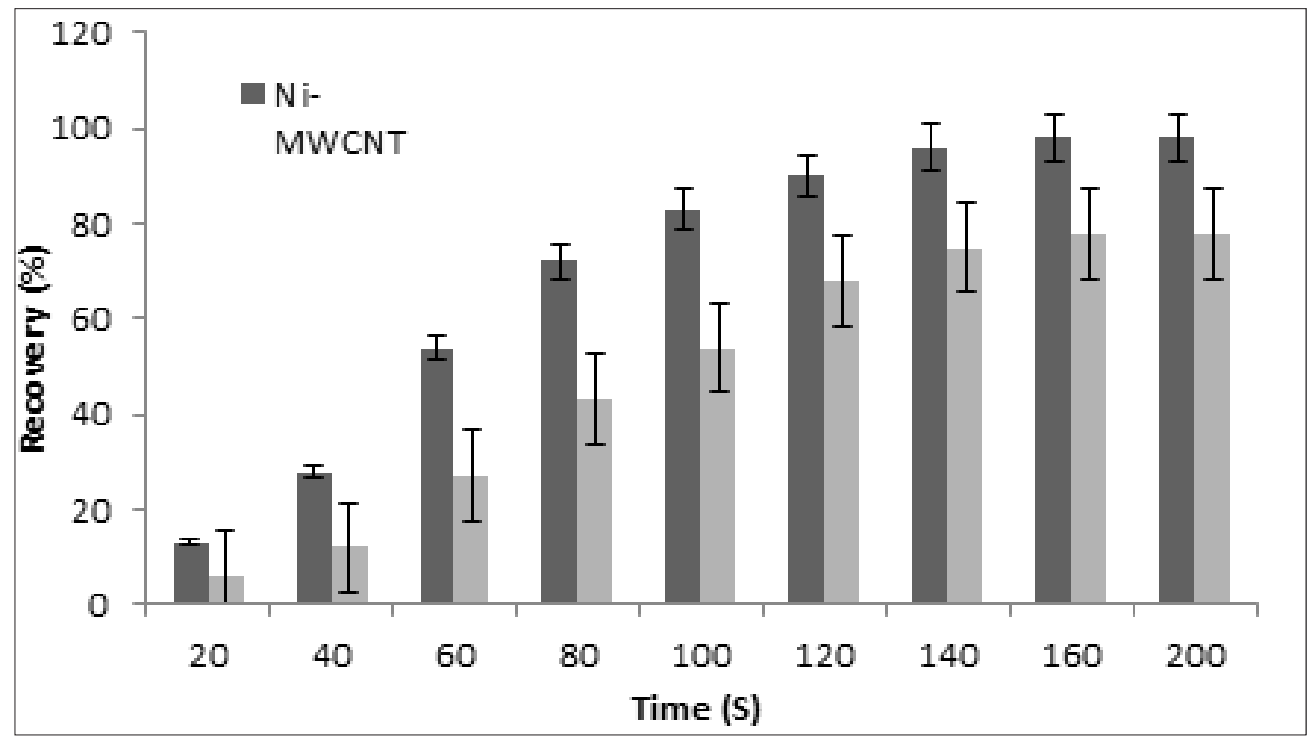

Fig. 5. The effect of time desorption of Ni-MWCNTs and MWCNTs by SGPR ( $\mathrm{n}=10)$. 


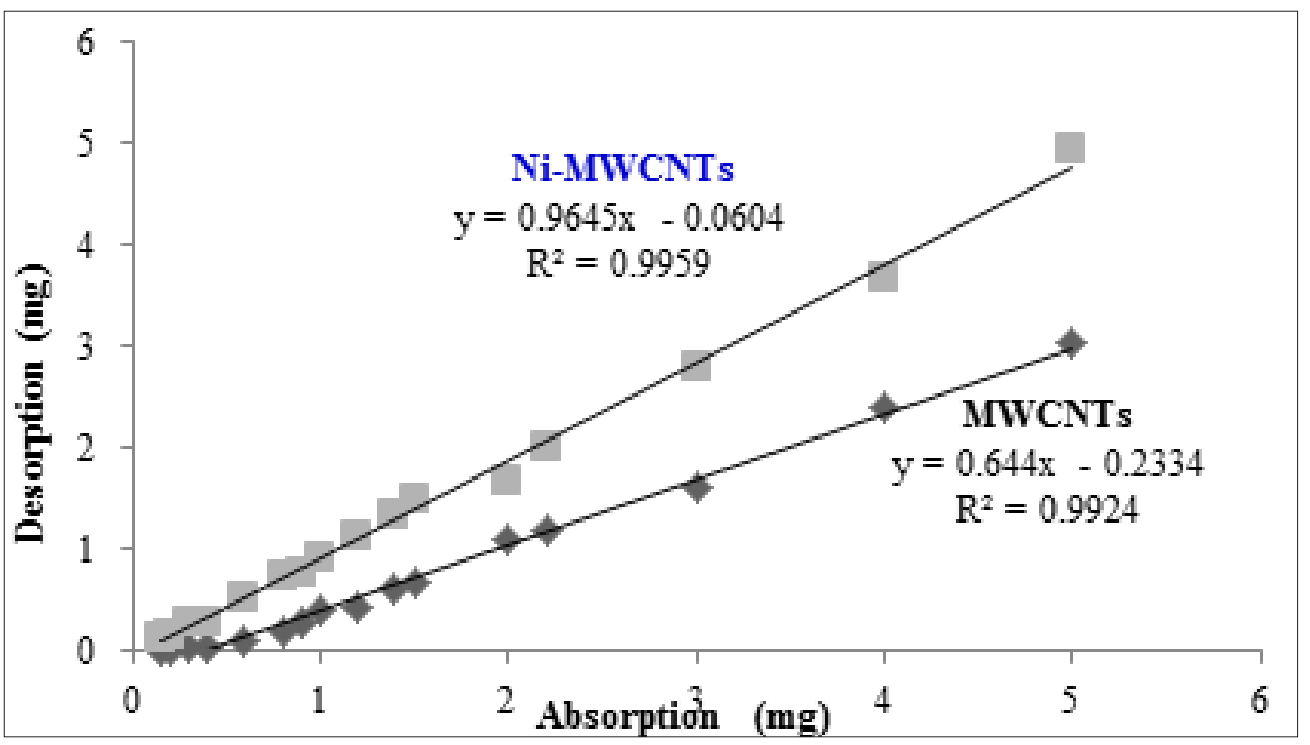

Fig. 6. The linear regression of adsorption / desorption for Ni-MWCNTs and MWCNTs

for desorption high efficiency was about $2.33 \mathrm{~min}$ with average desorption efficiency equals to 94.5 $98.2 \%$ by peak area mode (Fig. 5 ).

\subsection{Adsorption/desorption efficiency}

Removal efficiency and linear regression between the mean values of the mass adsorption and desorption by Ni-MWCNTs and MWCNTs have been shown in Figure 6. The mercury concentration (0.02-0.1 $\left.\mathrm{mg} \mathrm{L}^{-1}\right)$ was used for calculating of removal efficiency by proposed procedure. Based on Figure 6 the removal efficiency of Ni-MWCNTs (25 mg) was more than MWCNTs (25 mg) as compared to adsorption/desorption procedure for mercury removal from air by $200 \mathrm{ml} \mathrm{min}^{-1}$.

\subsection{Repeatability and retention time}

The retention time evaluated for $0.02-0.1 \mathrm{mg}$ of mercury concentration for Ni-MWCNTs and MWCNTs in different temperature. For calculation of retention time, the two ends of sorbents tube with Ni-MWCNTs and MWCNTs were kept at zero $0^{\circ} \mathrm{C}$ and $25^{\circ} \mathrm{C}$. After various times, carbon nanotubes were desorbed in optimum conditions $\left(200^{\circ} \mathrm{C}\right.$ and $10 \mathrm{~min}$ ) and then, this procedure followed in different times (1-5 weeks). The results showed us, the main mass of mercury in sorbent tubes was similar to primary mercury concentration after
3 weeks by desorption procedures $\left(0^{\circ} \mathrm{C}\right)$. But, in room temperature, only Ni-MWCNTs were stable mass after 1 week. So, Ni-MWCNTs is suitable sorbent for mercury removal from air and saving in room temperature. The adsorption / desorption procedure for Ni-MWCNTs and MWCNTs was repeated based on proposed method and after flashing point, 25 and 27 usage times was achieved as an optimum point for Ni-MWCNTs and MWCNTs, respectively.

\subsection{Discussions}

According to the results, Ni-MWCNTs were able to absorb mercury from air by SGPR. The atomic absorption spectrometer (GBC) Model (AAS-932 Puls) with cold vapor technique (HG3000) was used for determination of mercury in air, liquid and gas. Previous studies have been researched to attract mercury vapor in gas/air [23-27]. In this study, the Ni-MWCNTs with average diameter of (less than $100 \mathrm{~nm}$ ) were used to form a stationary phase (sorbent) of glass tubes containing a length of $10 \mathrm{~cm}$, internal diameter of $4 \mathrm{~cm}$ and external diameter of $6 \mathrm{~cm}[8,9]$. Shirkhanloo et al. used silver nanoparticles in glassy balls. They showed that silver nanoparticles (AgNPs) had good removal efficiency for mercury from air but it was more expensive as compared to our study. 
Also silver nanoparticles can be oxidizing by air, so storage is very hard in room temperature as compared to Ni-MWCNTs [7]. The average absorption rate and absorption capacity (AC) of mercury mass in different concentrations was increased by increasing the mass of nanotubes. In this study, the adsorption capacity of mercury for the Ni-MWCNTs $(\mathrm{Ni} \rightarrow \mathrm{Hg})$ was obtained 194 $\mathrm{mg} \mathrm{g}^{-1}$ which was higher than other published methods (less than $170 \mathrm{mg} \mathrm{g}^{-1}$ ) and MWCNTs (64 $\left.\mathrm{mg} \mathrm{g}^{-1}\right)$. This amount is more than the adsorption capacity of adsorptions such as activated carbon. [30]. According to results in optimized conditions, it seems that the factors such as, concentration of mercury in air, the mass of sorbents, air flow rate, surface area, temperature, and type of the adsorbent effected on the adsorption efficiency of mercury from air up to $80 \%$. Also, the other parameters such as layout of the sorbent tube, length, diameter, $\mathrm{O}_{2}$ and $\mathrm{H}_{2} \mathrm{O}$ in air, had low affected less than $20 \%$. The optimum point for concentration and temperature desorption was obtained 1-50 $\mathrm{gL}^{-1}$ and $200{ }^{\circ} \mathbf{C}$, respectively. In other studies that designed on the activated carbon, graphene and carbon nanotubes, similar to proposed method [31, 32]. After one month, the retention time of mercury on $\mathrm{Ni}$ MWCNTs, at temperature of $0^{\circ} \mathbf{C}$ was obtained $98.8 \% \pm 1.05$ was near to initial concentration amount. Many papers were used CNTs sorbents for removal mercury from air. The adsorption capacity of Ni-MWCNTs was higher than other sorbents such as MWCNTs, activated carbon and graphene which was previously reported.

\section{Conclusions}

In present work, a novel sorbent based on $\mathrm{Ni}$ MWCNTs was used for mercury removal from air by SGPR. By proposed procedure, the NiMWCNTs were synthesized and put on quartz glass cell. By laboratory bench scale set up, mercury generated in chamber and flowed to sorbent and by amalgamation procedure mercury removed from artificial pure air. After optimizing conditions, the adsorption and desorption point for Ni-MWCNTs was obtained $20-45^{\circ} \mathrm{C}$ and $200^{\circ} \mathrm{C}$, respectively.
The results showed us, the efficiency of mercury removal from air was more than $95 \%$ and less than $65 \%$ for Ni-MWCNTs and MWCNTs, respectively. The removal recovery was decreased less than $5 \%$ in present of $\mathrm{O}_{2}$ and $\mathrm{H}_{2} \mathrm{O}$ by SGPR method. $\mathrm{So}$, the Ni-MWCNTs introduced as novel sorbent with high efficiency for mercury removal from air in flow rate of $200 \mathrm{~mL}$ min-1 which was acted by physical and chemical adsorption mechanism.

\section{Acknowledgements}

This study was supported by Iranian petroleum industry health research institute and RIPI.

\section{References}

[1] A. Wilk, E. Kalisińska, D. I. Kosik-Bogacka, Cadmium, lead and mercury concentrations in pathologically altered human kidneys, Environ. Geochem. Health, 39 (2017) 889-899.

[2] B. Mansouri, R. Baramaki, M. Ebrahimpour, Acute toxicity bioassay of mercury and silver on Capoeta fusca (black fish), Toxicol. Indus. Health, 28 (2012) 393-398.

[3] M. Gochfeld, Cases of mercury exposure, bioavailability, and absorption, Ecotoxicol. Environ. Saf. J., 56 (2003) 174-179.

[4] R. Afrin, M. Y. Mia, M. A. Ahsan, A. Akbor, Concentration of heavy metals in available fish species in the Turag river, Bangladesh, Pakistan, J. Sci. Ind. Res., Series B: Biol. Sci., 58 (2015)104110.

[5] S. Cwan, Occupational toxicology, CRC Press. (2003) 317-319.

[6] PB. Tchounwou, WK. Ayensu, N. Ninashvili, D. Sutton, Environmental exposure to mercury and its toxicopathologic implications for public health, Environ. Toxicol. J., 18 (2003) 149-175.

[7] H. Shirkhanloo, M. Osanloo, M. Ghazaghi, H. Hassani, Validation of a new and cost-effective method for mercury vapor removal based on silver nanoparticles coating on micro glassy balls, Atmos. Pollut. Res., 8 (2017) 359-365

[8] NIOSH Manual of analytical methods (NMAM, 5 Edition), U.S. department of health and human services, 2017.

[9] Occupational Safety and Health Administration (OSHA), Air contaminants, 29 CFR 
1910.1000,2017. http:/www.osha.gov/laws- regs/ regulations/standardnumber/1910/1910.1000.

[10] M. Marczak, S. Budzyń, J. Szczurowski, K. Kogut, P. Burmistrz, Active methods of mercury removal from flue gases, Environ. Sci. Pollut. Res. Int., 26 (2019) 8383-8392.

[11] JG. Evan, WP. Henry, AH. Richard, Novel sorbents for mercury removal from flue gas, Ind. Eng. Chem. Res., 39 (2000) 1020-1029.

[12] Wu. Xiang, D. Yufeng, Li. Na, Hu. Peng, Y.Ting, M. Jialin, R. Shaojun, W. Hongqi, Regenerable $\mathrm{Ce}-\mathrm{Mn} / \mathrm{TiO}_{2}$ catalytic sorbent for mercury removal with high resistance to $\mathrm{SO}_{2}$. Energ. Fuel., 33(2019) 8835-8842.

[13] M. Lingjun, Y. Caixia, Y. Liang, H. Qihuang, H. Lina, C Liping, B Weiren, W Jiancheng, Effects of supports on $\mathrm{Pd}-\mathrm{Fe}$ bimetallic sorbents for $\mathrm{Hg}^{0}$ removal activity and regeneration performance from coal-derived fuel gas, Energ. Fuel., 33 (2019) 8976-8984.

[14] Z. Xiaoyang, C. Lin, L. Yuzhong, Z. Yongchun, D Yong, C Shensong, Adsorption and oxidation of mercury by montmorillonite powder modified with different copper compounds, Energ. Fuel., 33 (2019) 7852-7860.

[15] M. Jian, W. Chang, K. Lingnan, L. Xiaoli, H, Qixing, Z Hui, Y. Shijian, Outstanding performance of recyclable amorphous $\mathrm{MoS}_{3}$ supported on $\mathrm{TiO}_{2}$ for capturing high concentrations of gaseous elemental mercury: mechanism, kinetics, and application., Environ. Sci. Technol., 53 (2019) 4480-4489.

[16] F. Seef Saadi, KA. Mohamed, J. Wan Zurina Binti, A. Mohammed Abdulhakim A, F. Sabah Saadi, K. Suhana Binti, L. Sai Hin, C. Ming Fai, A. Ali Najah, ES. Ahmed, Artificial neural network approach for modelling of mercury ions removal from water using functionalized CNTs with deep eutectic solvent, Int. J. Mol. Sci., 17( 2019) 4206-4212.

[17] S.S. Fiyadh, M.A. AlSaadi, .M.K AlOmar, S.S. Fayaed, A.R. Hama, S. Bee, A. El-Shafie, The modelling of lead removal from water by deep eutectic solvents functionalized CNTs: Artificial neural network (ANN) approach, Water Sci. Technol., 76( 2017) 2413-2426.

[18] S.S. Fiyadh, M.A. AlSaadi, .M.K AlOmar, S.S. Fayaed, A. El-Shafie, Lead removal from water using DES functionalized CNTs: ANN modeling approach. Desalin. Water Treat., 150(2019) 105-
113.

[19] M.A. AlSaadi, A. Al Mamun A., Alam M.Z., Amosa M.K., Atieh M.A. Removal of cadmium from water by CNT-PAC composite: Effect of functionalization, Nano., 11(2016) 1650011.

[20] M. Lu M, T, Ohba, K. Kaneko, K. Hata, M. Yumura, S. Iijima, H. Komatsu, A. Sakuma, H. Kanoh, Electron density modification of single wall carbon nanotubes (SWCNT) by liquid-phase molecular adsorption of hexaiodobenzene., Materials., 6(2013) 535-543.

[21] R. Yan, D.T. Liang, J.H. Tay, Control of mercury vapor emissions from combustion flue gas. Environ. Sci. Pollut. Res., J., 10 (2003) 399-407.

[22] PM. Ajayan, O.Z. Zhou, Applications of carbon nanotubes, Carbon Nanotubes J., 80 (2001) 391425.

[23] P.E. Díaz-Flores, J.A. Arcibar-Orozco, N.V. PerezAguilar, J.R. Rangel-Mendez, V.M. Ovando Medina, J.A. Alcalá-Jáuegui, Adsorption of organic compounds onto multiwall and nitrogen-doped carbon nanotubes: Insights into the adsorption mechanisms, Water, Air Soil Pollut. J., 228 (2017) 133- 147.

[24] J. Xu, Z. Cao, Y. Zhang, Z. Yuan, Z. Lou, X. Xu, X. Wang, A review of functionalized carbon nanotubes and graphene for heavy metal adsorption from water: Preparation, application, and mechanism, Chemosphere. J., 195 (2018) 351- 364.

[25] W.N. Nyairo, Y. Ramazan Eker, C. Kowenje, I. Akin, H. Bingol, A. Tor, D.M. Ongeri. Efficient adsorption of lead (II) and copper (II) from aqueous phase using oxidized multiwalled carbon nanotubes/polypyrrole composite, Sep. Scie. Technol. J., 52(2018) 1498-1510.

[26] O. Moradi, K. Zare, M. Yari, Interaction of some heavy metal ions with single walled carbon nanotube, Int. J. Nano Dimens., 1 (2011) 203-20.

[27] F. Su, C. Lu, S. Hu, Adsorption of benzene, toluene, ethylbenzene and p-xylene by $\mathrm{NaOCl}$ oxidized carbon nanotubes, Colloids Surf., A Physicochem. Eng. Asp., 353 (2010) 83-91.

[28] A. Safavi, N. Maleki, M.M. Doroodmand, Fabrication of a selective mercury sensor based on the adsorption of cold vapor of mercury on carbon nanotubes: Determination of mercury in industrial wastewater, J. Hazard. Mater., 173 (2010) 622-9. 
[29] C.K Kuo, Desorption and re-adsorption of carbon nanotubes: Comparissons of sodium hydroxiid and microwave irradiation processes, J. Hazard. Mater., 152 (2008) 949-54.

[30] E. Granite, H. Pennline, R. Hargis, Novel sorbents for mercury removal from flue gas, Ind. Eng. Chem. Res., J., 39 (2000) 1020-1029.

[31] S.E. Lindberg, W.J, Stratton, Atmospheric mercury speciation, concentrations and behavior of reactive gaseous mercury in ambient air, Environ. Sci. Technol., 32 (1998) 49-57.

[32] T.G. Lee, Comprison of Hg captuer efficiencies of three in situ generated sorbent, Environ. Energy Eng., AIChE J., 47 (2001) 954-961. 